\title{
Methodology for Finding Maximum Performance and Improvement Possibility of Rule-Based Control for Parallel Type-2 Hybrid Electric Vehicles
}

\author{
Haeseong Jeoung, Kiwook Lee and Namwook Kim * \\ Machine Dynamics Laboratory, Department of Mechanical Engineering, Hanyang University, Gyeonggi-do, \\ Ansan 15588, Korea; hsjeoung00@gmail.com (H.J.); kwlee345@gmail.com (K.L.) \\ * Correspondence: nwkim21@gmail.com
}

Received: 15 April 2019; Accepted: 16 May 2019; Published: 20 May 2019

\begin{abstract}
Hybrid electric vehicles (HEVs) require supervisory controllers to distribute the propulsion power from sources like an engine and motors. Control concepts based on optimal control theories such as dynamic programming (DP) and Pontryagin's minimum principle (PMP) have been studied to maximize fuel efficiencies. These concepts are, however, not practical for real-world applications because they guarantee optimality only if future driving information is given prior to the actual driving. Instead, heuristic rule-based control concepts are widely used in real-world applications. Those concepts are not only simple enough to be designed based on existing vehicle control concepts, but also allow developers to easily intervene in the control to enhance other vital aspects of real-world vehicle performances, such as safety and drivability. In this study, a rule-based control for parallel type-2 HEVs is developed based on representative control concepts of real-world HEVs, and optimal control parameters are determined by optimization processes. The performance of the optimized rule-based control is evaluated by comparing it with the optimal results obtained by PMP, and it shows that the rule-based concepts can achieve high fuel efficiencies, which are close, typically within $4 \%$, to the maximum values obtained by PMP.
\end{abstract}

Keywords: optimization; P2 HEV; rule-based control; large-scale simulation

\section{Introduction}

The depletion of fossil fuels is a global energy issue that is becoming more serious even as industrial demand for oil increases [1]. To make matters worse, $\mathrm{CO}_{2}$ emissions from fossil fuels and industry are dramatically growing [2]. Thus, efforts are intensifying to save energy across all sectors. Particularly in the transportation sector, energy-saving efforts have accelerated, with many countries having strengthened $\mathrm{CO}_{2}$ regulations for vehicles [3-5]. As alternatives to conventional vehicles, hybrid electric vehicles (HEVs) are a promising solution to save fuel and meet regulations. To improve the fuel efficiencies of HEVs, various types of powertrain configurations have been developed in the last two decades, varying in the layout of the transmission and the power sources; these include the series hybrid, parallel hybrid, power split hybrid, and multi-mode hybrid [6,7]. The power split hybrid system [8], represented by the Toyota Prius [9] which was introduced in 1997, has been considered to be a promising solution for vehicle hybridization $[10,11]$, but a parallel hybrid system, applied in other vehicles like the Hyundai Ioniq, has recently shown outstanding performance in fuel efficiency that is close to or outperforms the power split hybrid system [12].

On the other hand, the fuel efficiencies of HEVs can differ significantly according to the performance of the supervisory control, and especially the energy management strategy. In essence, an HEV will not be able to fully utilize its electric power if its controllers fail to balance the state of charge (SOC) 
of the battery, which would result in low fuel efficiencies. Therefore, control concepts are vitally important to maximize HEV fuel efficiencies. There has been a great deal of previous research on control concepts using fuzzy logic [13], battery on/off [14], and equivalent consumption minimization strategy (ECMS) [15]. Among them, an adoptive ECMS strategy shows a great deal of progress [16,17]. Several studies have shown that control concepts based on optimal control theories such as dynamic programming (DP) $[18,19]$ or Pontryagin's minimum principle (PMP) $[20,21]$ can produce excellent results in minimizing HEV fuel consumption. These control concepts, however, are not preferred solutions for real-world applications [22]. The optimal control theories are computationally intensive and are not straightforward for engineers to understand; thus, they are also difficult to modify to include other commercially important requirements such as safety, drivability, robustness, and stability [23]. For instance, when control developers attempt to minimize the round-trip energy in the battery to improve its durability, it is not easy to manipulate the control solution obtained by using DP or PMP because these theories generally provide only the final control solutions. Therefore, real-world HEVs have employed heuristic rule-based control concepts to distribute the power between the engine and motors and to balance the SOC [24]. The control concepts used in real-world HEVs pursue high fuel efficiency by improving the operational efficiency of the engine or reducing the round-trip loss of the battery $[25,26]$.

Numerous direct methods for parametric optimization have been proposed. The election, crossover, and mutation processes through a memetic algorithm (MA), which has a great performance in searching the locally optimal value, was used to determine the optimal parameters for parallel type-2 HEVs (P2 HEVs) [27]. Research has also been conducted to solve the same problem through simulated annealing particle swarm optimization (SA-PSO) [28]. A grey wolf optimizer (GWO) which was made by imitating the hunting method of wolves was proposed to find the optimal variables for the battery control [29]. One of the global direct methods, called the dividing rectangle (DIRECT) algorithm, was applied to find the optimal set of control parameters for P2 HEVs [30]. A fast non-dominated sorting genetic algorithm-II (NSGA-II) was proposed to solve the multi-objective optimization problem for HEVs considering fuel economy, drivability, and emission [31]. The parametric optimization problem for HEVs is difficult to search the globally optimal value due to the coupled terms and nonlinearity of the system. Thus, the main topic was how to find the optimal parameters of rule-based control for HEVs by using a new optimization method which had not been used before, as we have seen in previous research.

The purpose of this study was to propose a methodology for deriving the maximum performance and the possibility of the potential improvement of the rule-based controller. A generic rule-based control for parallel type-2 HEVs (P2 HEVs) was developed based on the ideas used in real-world HEVs, and an optimization process to determine the optimal control parameters was introduced. First, this study provides evaluation results of the rule-based control, including a comparison of simulation results of the rule-based control with optimal fuel consumption results of the PMP control. This is meaningful because it demonstrates the maximum performance of the real-world control concept and how close its performance is to optimal results. Second, this study also provides an optimization process and an evaluation methodology for the controller. To determine the best key parameters, two optimization processes were used in this study. One was a large-scale simulation (LSS) to study the impact of SOC on the fuel consumption, and the other was a pattern search (PS), one of the direct methods of optimization, to reduce the processing time required for finding the optimal parameters [32]. These two processes and their comparative results will provide insights for other engineers in selecting appropriate optimization processes as they design controllers. Finally, simulation results obtained from the rule-based control with optimized control parameters were evaluated based on the performance of the PMP control, which is the evaluation reference. 


\section{Rule-Based Control for P2 HEVs}

The P2 HEV has a simple powertrain configuration in which a single motor is mounted between the engine clutch and the transmission. The powertrain system can utilize electric vehicle (EV) mode by turning off the engine, and the motor assists the engine if the clutch is engaged and the engine is turned on (Figure 1) [6,33]. Compared to the power split hybrid system, the P2 HEV achieves higher fuel efficiency in highway driving by avoiding the power recirculation loss in the electronic continuously variable transmission (e-CVT) at high speed [34-36]. The P2 HEV is, however, not able to optimize the engine operating point because its engine speed is constrained by the transmission gear ratio. According to United States Environmental Protection Agency's (US EPA's) 2018 fuel economy test results, the Hyundai Ioniq, which implements the P2 configuration, shows better fuel economy in a highway driving cycle but lower fuel economy in an urban driving cycle compared to the Toyota Prius, a representative power split hybrid system [25].

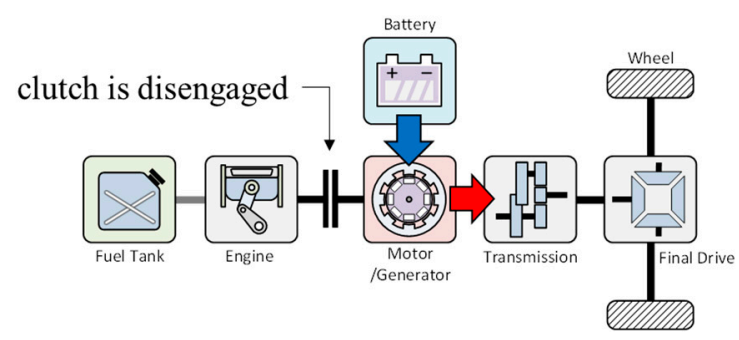

(a)

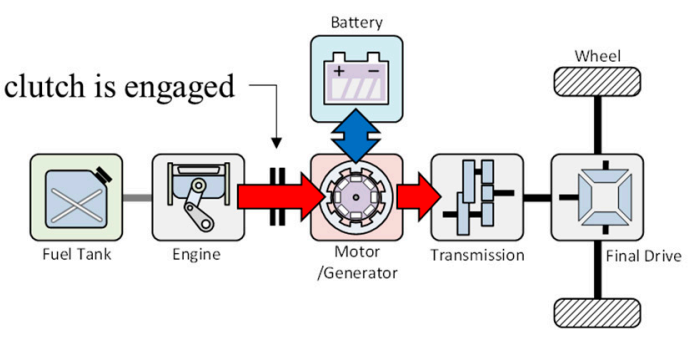

(b)

Figure 1. Powertrain configuration of a parallel type-2 hybrid electric vehicle (P2 HEV) with power flow in (a) electric vehicle (EV) mode and (b) HEV mode.

Regarding P2 HEV control, the torque generated by the motor can be added to the engine torque while the speed of the engine and the motor can be optimized by controlling the gear shift of the transmission, which enables the engine torque to be optimal. The vehicle model in Autonomie, a powertrain analysis tool developed by Argonne National Laboratory, was used herein to evaluate the performance of the control (Figure 2) [24]. The vehicle model was built in a Matlab Simulink environment, and the controller was also developed as a Simulink model. Vehicle specifications are listed in Table 1.

Table 1. Vehicle specifications.

\begin{tabular}{|c|c|}
\hline Engine Max. Power/Torque & $76 \mathrm{~kW} / 156 \mathrm{Nm}$ \\
\hline Motor Max. Power/Torque & $34 \mathrm{~kW} / 260 \mathrm{Nm}$ \\
\hline Battery Max. Power/Capacity & $63 \mathrm{~kW} / 7.04 \mathrm{Ah}$ \\
\hline Gear Ratio & $\# 1) 2.563 \# 2) 1.552$ \#3) 1.022 \#4) 0.727 \#5) 0.520 \\
\hline Total Mass & $1700 \mathrm{~kg}$ \\
\hline
\end{tabular}

The control strategy for P2 HEVs can be divided into two main phases. The first phase determines whether the engine should be turned on. If it is not, the motor must provide all the required power. In the second phase, if the engine is turned on, the controller should determine how to distribute the power between the engine and the motor to satisfy the power demand. All details on the control concept used in the rule-based control are introduced in this section. 


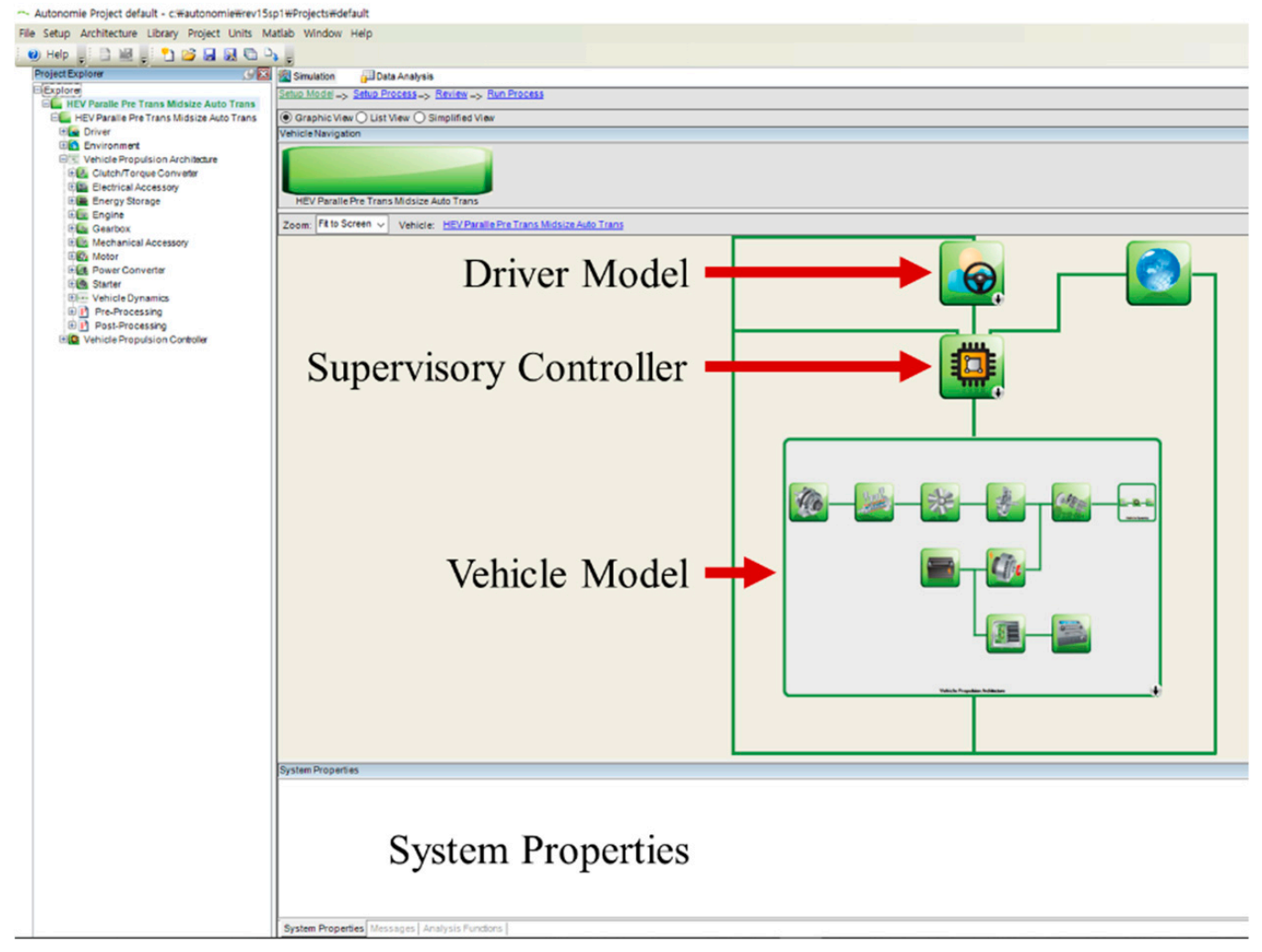

Figure 2. Vehicle model of a P2 HEV in Autonomie.

\subsection{Engine On/Off Control}

If the engine does not achieve high operational efficiency, the P2 HEV operates in EV mode, using the motor as the sole source of the propulsion power. The vehicle turns on the engine and switches from EV mode to HEV mode when it encounters a certain condition. There are several factors involved in this decision, but three primary control parameters are considered in our controller-torque threshold, speed threshold, and power threshold. The wheel torque demand is calculated using the accelerator pedal signal (APS) and the wheel speed is calculated from the vehicle speed. The control concept for the engine on/off decision is defined using the three control parameters as illustrated in Figure 3.

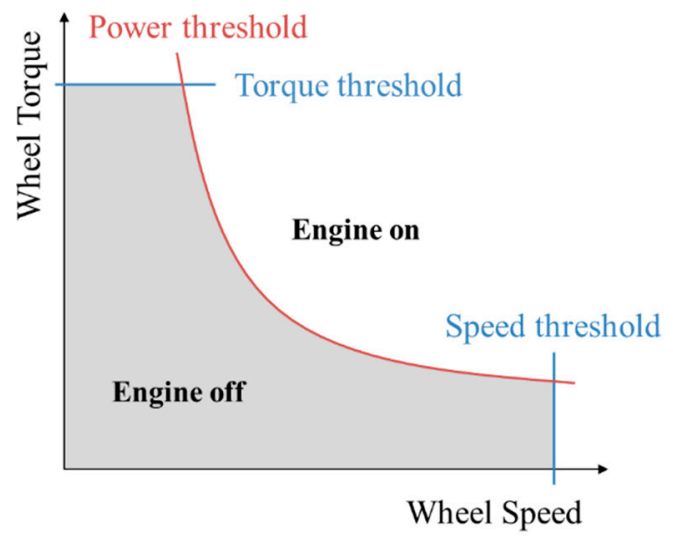

Figure 3. Main factors for engine on/off control. 


\subsection{Power Distribution Control}

Once the engine has started, the controller should distribute the engine power and the motor power to improve the system efficiency. There are two preferred control strategies for the power distribution. The first strategy is to prioritize the maximization of engine efficiency. In this strategy, the engine tries to operate along its optimal operating line (OOL) whenever possible, and the motor $\left(T_{\text {mot }}\right)$ assists the engine to meet the driver's torque demand $\left(T_{d m d}\right)$, which can be expressed as Equations (1) and (2):

$$
\begin{gathered}
T_{\text {eng }}^{\mathrm{OOL}}=f\left(\omega_{\text {eng }}\right), \\
T_{m o t}=T_{d m d}-T_{\text {eng }}^{\mathrm{OOL}} .
\end{gathered}
$$

Figure 4 shows the concept of this control-the engine torque is determined first, and the motor torque is then determined as the difference between the torque demand and the engine torque $[26,37,38]$. This strategy is hereinafter termed the engine OOL strategy.
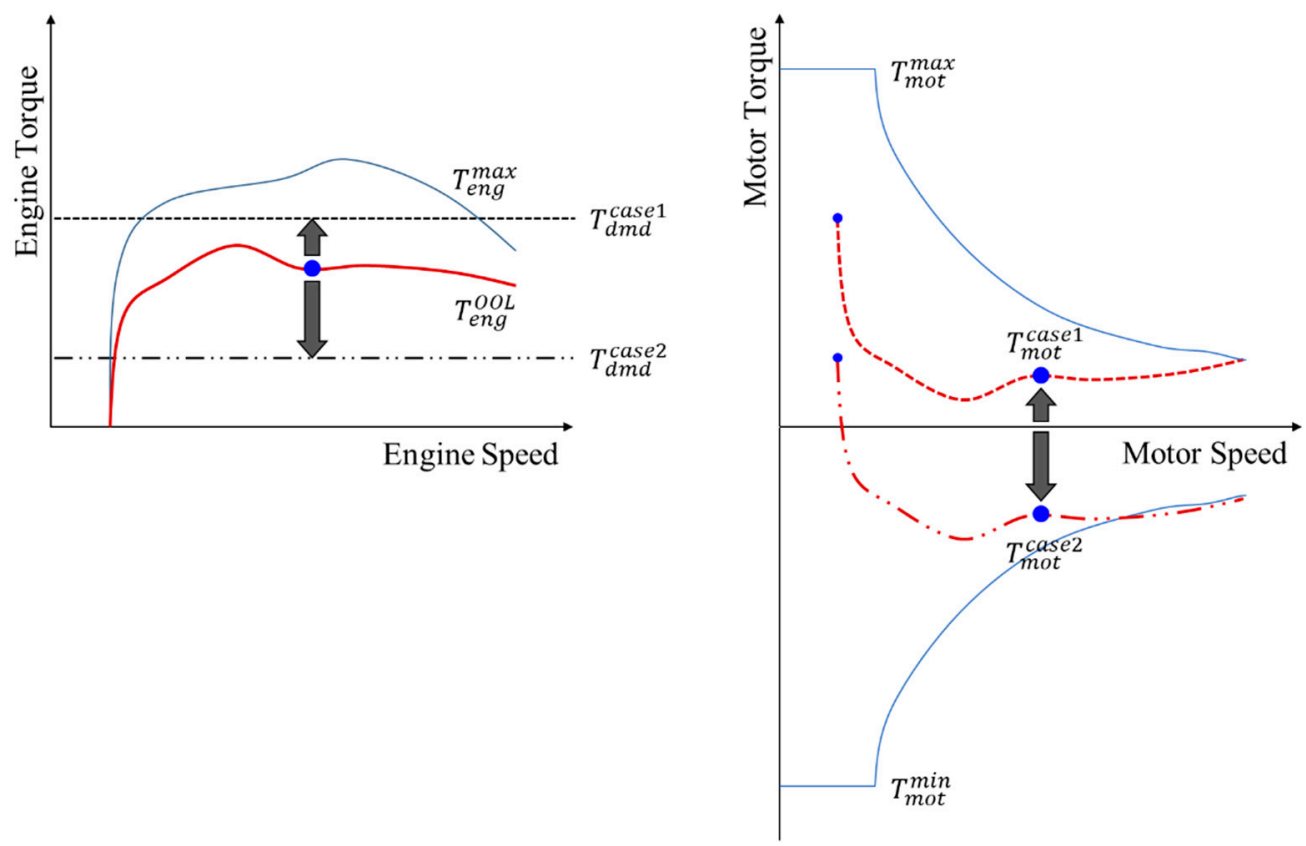

Figure 4. The motor assists by providing a positive or negative torque depending on whether the torque demand is larger or smaller than the engine torque determined along the engine optimal operating line (OOL).

The second strategy focuses on the management of the SOC of the battery. In this strategy, the battery power demand is determined to maintain the SOC at a desired level, which is generally the initial SOC of HEVs [37]. Based on the electric power demand $\left(P_{m o t}\right)$, the motor torque is determined according to its speed, and the engine provides an appropriate torque to satisfy the driver's torque demand, as shown in Equations (3)-(5). In Equation (3), $s_{+}$and $s_{-}$are arbitrary positive values representing the slope to determine the rate of charging and discharging, respectively.

$$
\begin{aligned}
& p_{\text {mot }}=\left\{\begin{array}{c}
p_{\text {max }}, \text { if } \mathrm{SOC} \in \mathrm{SOC}_{\text {high }} \\
s_{+} \times\left(\mathrm{SOC}-\mathrm{SOC}_{r e f}\right), \text { if } \mathrm{SOC} \geq \mathrm{SOC}_{r e f} \text { and } \mathrm{SOC} \in \mathrm{SOC}_{\text {normal }} \\
s_{-} \times\left(\mathrm{SOC}-\mathrm{SOC}_{r e f}\right), \text { if } \mathrm{SOC}<\mathrm{SOC}_{r e f} \text { and } \mathrm{SOC} \in \mathrm{SOC}_{\text {normal }} \\
P_{\text {min }}, \text { if SOC } \in \mathrm{SOC}_{\text {low }}
\end{array},\right. \\
& \mathrm{T}_{\text {mot }}=\frac{P_{m o t}}{\omega_{m o t}},
\end{aligned}
$$




$$
T_{\text {eng }}=T_{\text {dmd }}-T_{\text {mot }} .
$$

Figure 5 shows the concept of this control graphically. This strategy is hereinafter termed the SOC balancing strategy.

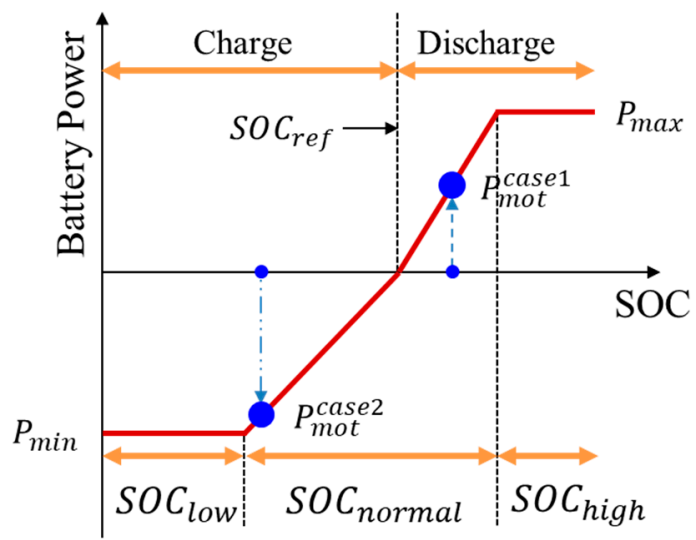

(a)
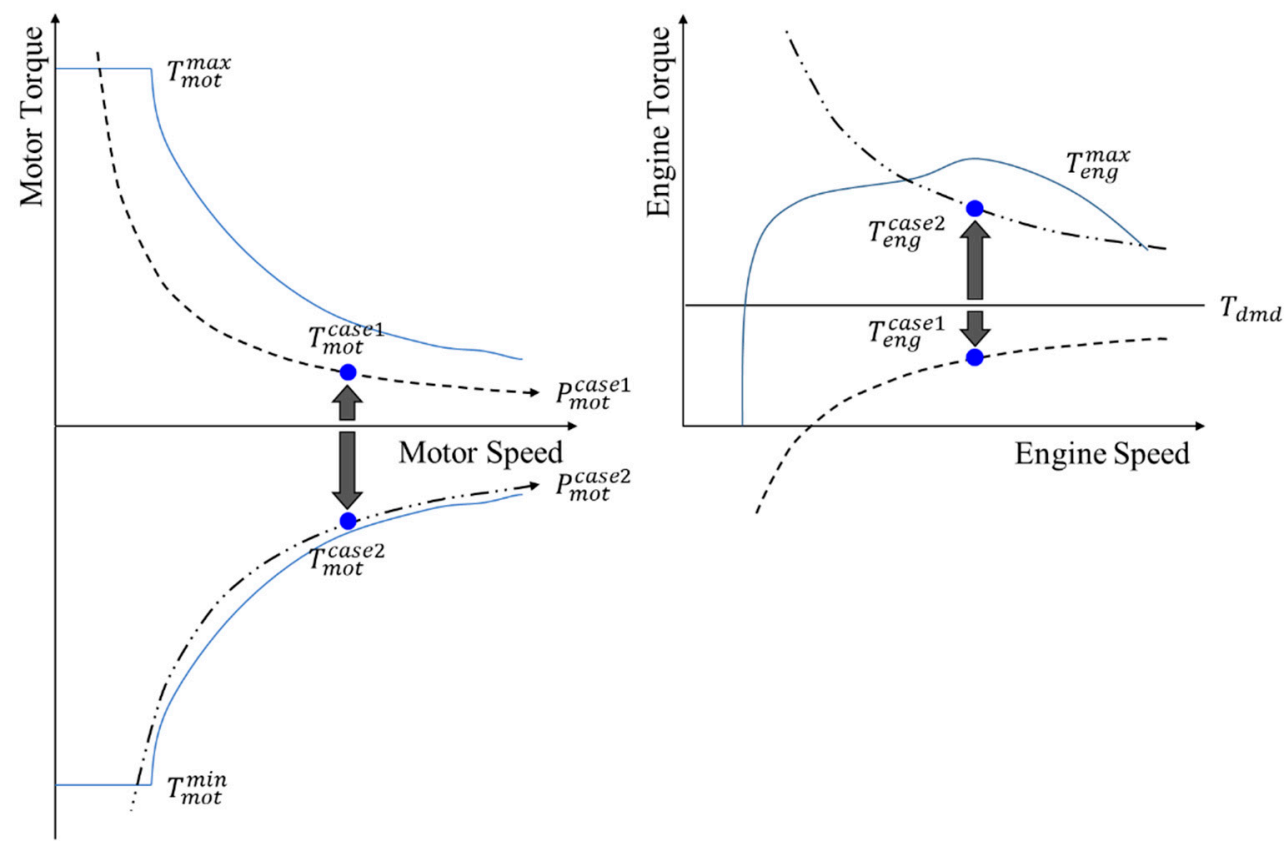

(b)

Figure 5. (a) The battery power demand is determined according to the state of charge (SOC) reference; (b) the motor torque is determined by the battery power, and then the engine assists if needed.

In this control concept, the charging and discharging rates can be used as the control parameters, and the motor is used aggressively to return the SOC to its initial level. The engine OOL strategy is preferred in HEVs that utilize fixed gear ratios. The Hyundai Sonata HEV and the Hyundai Ioniq have implemented this control concept to maximize their engine efficiencies. It is known that the fixed ratio modes employed in the GM Voltec 1st gen. and the Honda Accord Hybrid also use engine torque manipulation to utilize high operational efficiencies $[26,38]$. On the other hand, the SOC balancing strategy is preferred for HEVs using e-CVT because those systems are able to follow the engine's OOL with the transmission's control. The Toyota Prius generally uses the motors to restore the SOC to its initial level if the engine is turned on [9-11]. In fact, this control reduces the round-trip loss caused by energy conversions between mechanical and electrochemical energy. In summary, the engine OOL 
strategy tries to increase the engine efficiency whereas the SOC balancing strategy tries to reduce the energy conversion loss (Figure 6).
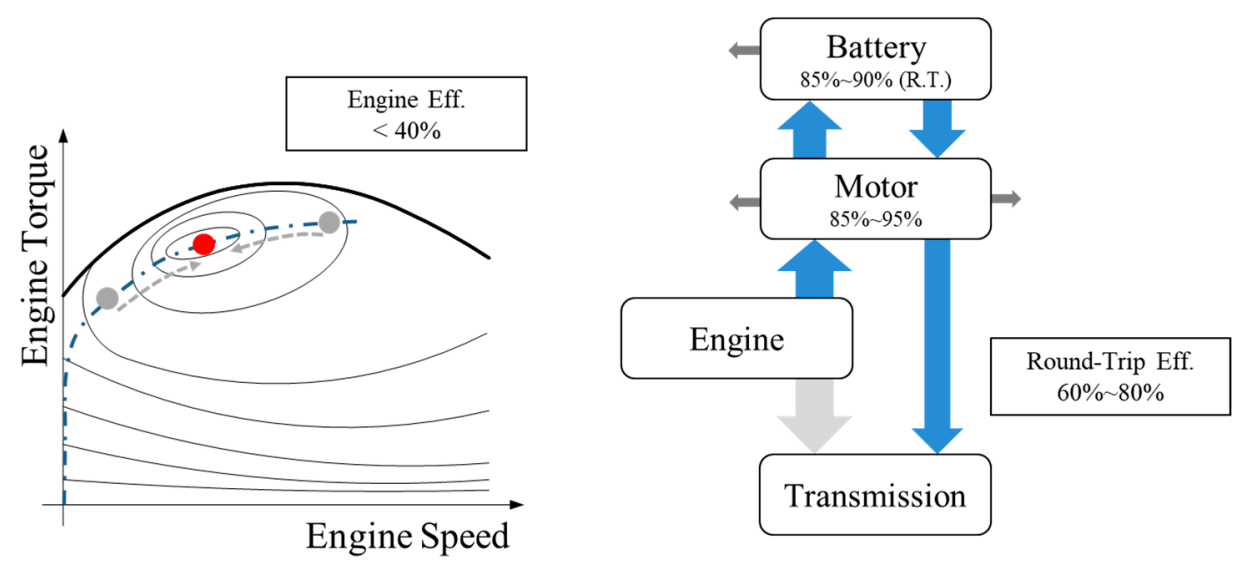

Figure 6. Impacts of the power distribution strategy on the system efficiency: Engine OOL strategy vs. SOC balancing strategy.

To develop a generic control model, these two strategies can be combined with the use of a weighting factor $w$ to determine the final power distribution between the engine and the motor (Figure 7). The value of $w$ is between zero and one; one corresponds to full use of the engine OOL strategy and zero corresponds to full use of the SOC balancing strategy. The optimal engine torque is determined using the two engine torques calculated according to the two strategies as shown in Equations (6)-(9). The motor assists in making up the rest of the torque. Figure 8 shows the flow chart of the proposed supervisory control algorithm for P2 HEVs.

$$
\begin{gathered}
T_{\text {eng }}^{1}=T_{\text {eng }}^{\mathrm{OOL}}=f\left(\omega_{\text {eng }}\right), \\
T_{\text {eng }}^{2}=T_{\text {dmd }}-\frac{P_{\text {mot }}}{\omega_{\text {mot }}}, \\
T_{\text {eng }}^{\text {final }}=w T_{\text {eng }}^{1}+(1-w) T_{\text {eng }}^{2}, 0 \leq \mathrm{w} \leq 1, \\
T_{\text {mot }}^{\text {final }}=T_{\text {dmd }}-T_{\text {eng }}^{f i n a l} .
\end{gathered}
$$

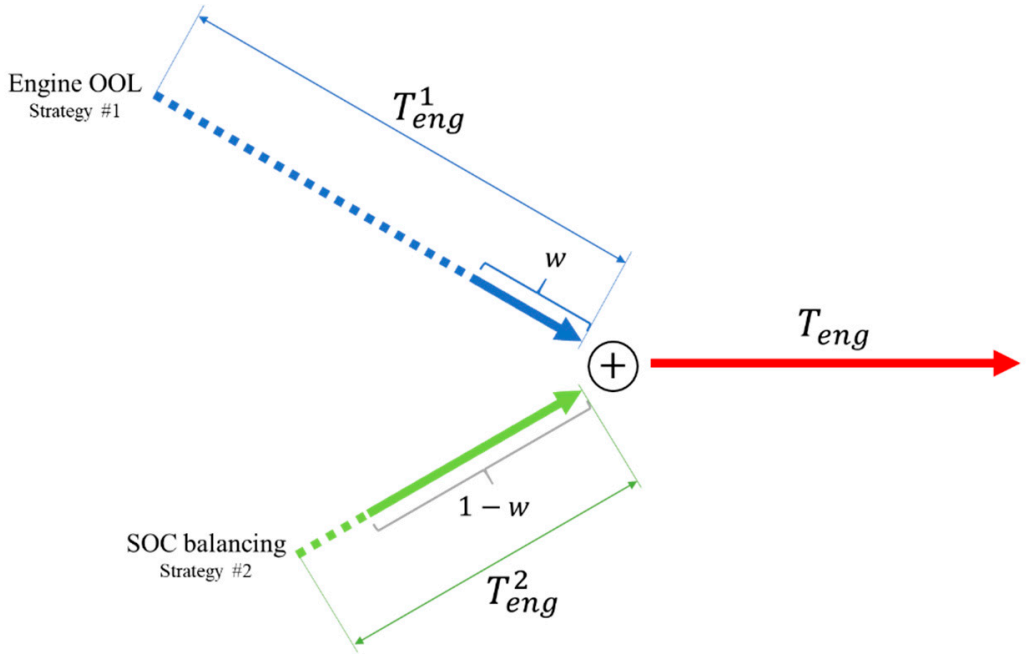

Figure 7. Mixed engine torque obtained from using the two strategies together. 


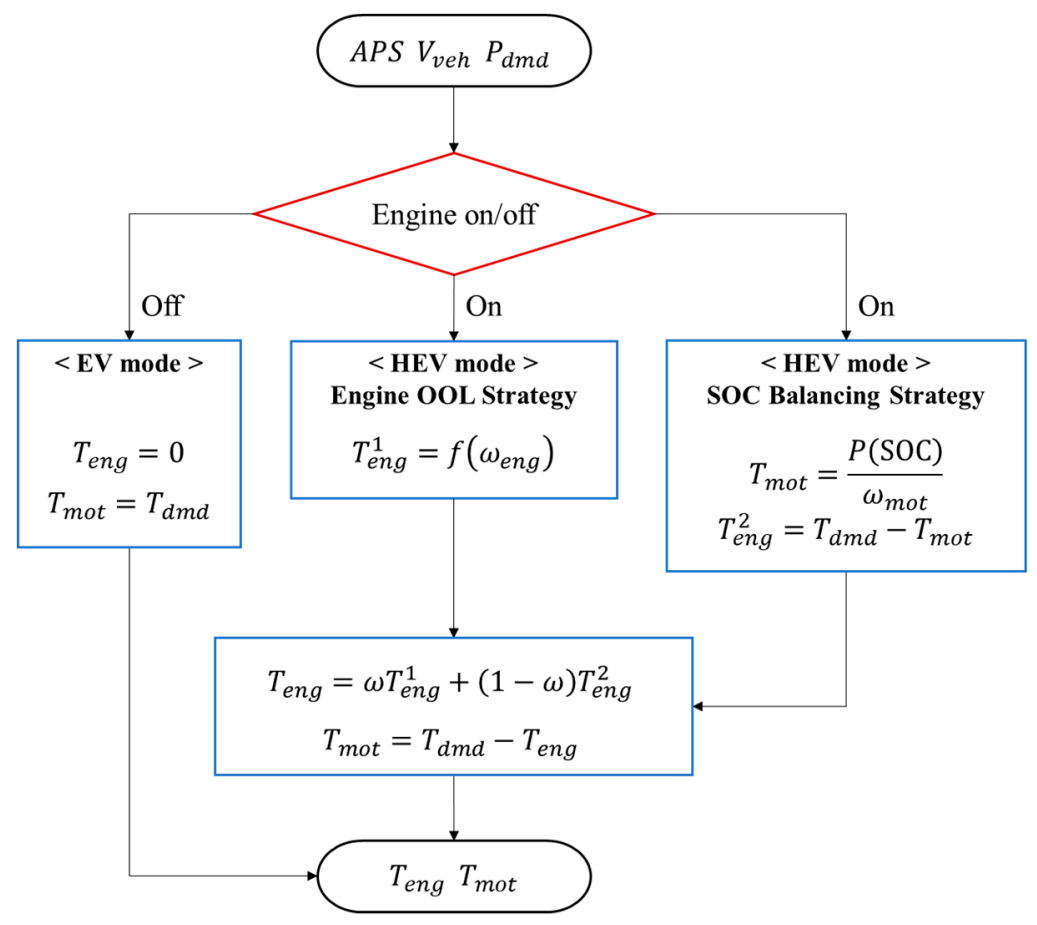

Figure 8. Flow chart for the two-phase control strategy for P2 HEVs.

\subsection{Primary Control Parameters}

Although there could be many control parameters in a rule-based control, six key parameters that significantly affect the control aspects were selected to be optimized-three for the engine on/off control, two for the SOC balancing control, and one weighting factor $w$ for mixing the power distribution strategy. Table 2 shows information about the selected control parameters.

Table 2. Key parameters used for control.

\begin{tabular}{clccc}
\hline Strategy & \multicolumn{1}{c}{ Parameter } & Upper and Lower Boundary & Unit \\
\hline \multirow{3}{*}{ Engine OOL } & $(\# 1)$ APS threshold & 0.1 & 0.9 & Normalized \\
& $(\# 2)$ Speed threshold & 18 & 131 & $\mathrm{~km} / \mathrm{h}$ \\
& $(\# 3)$ Power threshold & 3 & 34 & $\mathrm{~kW}$ \\
\hline \multirow{2}{*}{ SOC Balancing } & $(\# 4)$ Power slope (discharge) & 25 & 150 & $\mathrm{~kW} / \%$ \\
& $(\# 5)$ Power slope (charge) & 37 & 150 & $\mathrm{~kW} / \%$ \\
\hline Mixed & $(\# 6)$ Weighting factor & 0 & 1 & Normalized \\
\hline
\end{tabular}

\section{Control Optimization}

In the control problems of HEVs, the objective of the control is to minimize the fuel consumption, which can be expressed as Equation (10). Meanwhile, the final SOC should be the same as the initial SOC, as shown in Equation (11), because there can be no fair comparison of the fuel consumption if

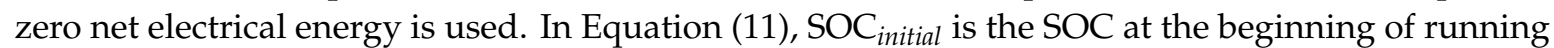
the simulation, and $\mathrm{SOC}_{\text {final }}$ is the SOC at the end of running the simulation. The final supervisory control algorithm uses Equations (8) and (9), which determine the engine torque demand and the motor torque demand. The relationship between Equations (8) and (11) gives us the intuition to select the key parameters. Although all parameters are linked together, the objective function, that is the total fuel consumption, directly depends on the engine torque and speed. Thus, three thresholds used for engine on/off control are selected as key parameters. Likewise, the constraint of SOC depends on the motor torque and speed. Thus, the parameters which determine the charge and discharge rate 
of battery are selected as key parameters. Finally, the parameter to determine the weight of the two strategies is naturally picked.

$$
\begin{gathered}
\min J=\int_{0}^{t_{f}} \dot{m}_{\text {fuel }}\left(T_{\text {eng }}^{\text {final }}, \omega_{\text {eng }}\right) d t, \\
\mathrm{SOC}_{\text {initial }}=\mathrm{SOC}_{\text {final }}=60 .
\end{gathered}
$$

The rule-based controller is optimized by determining the best value for each of the six control parameters listed in Table 2 that maximize the fuel economy in the standard driving cycles HWFET, SC03, UDDS, US06, and WLTC. To determine the optimal parameters, two processes are proposed in this study, the large-scale simulation and the pattern search. Simply, LSS evaluates all available combinations of the parameters whereas PS searches for optimal parameter values using a numerical optimization process. To evaluate the performance of each rule-based control, we used the optimal control results obtained by applying Pontryagin's minimum principle to establish reference performances.

\subsection{Large-Scale Simulation (LSS)}

The LSS for the parametric optimization was conducted in a cloud-based computational environment, in which 20 node PCs with 80 cores for individual simulations were connected to cloud storage (Figure 9). The purpose of LSS was to examine all fuel consumption values for every possible combination of the control parameters.

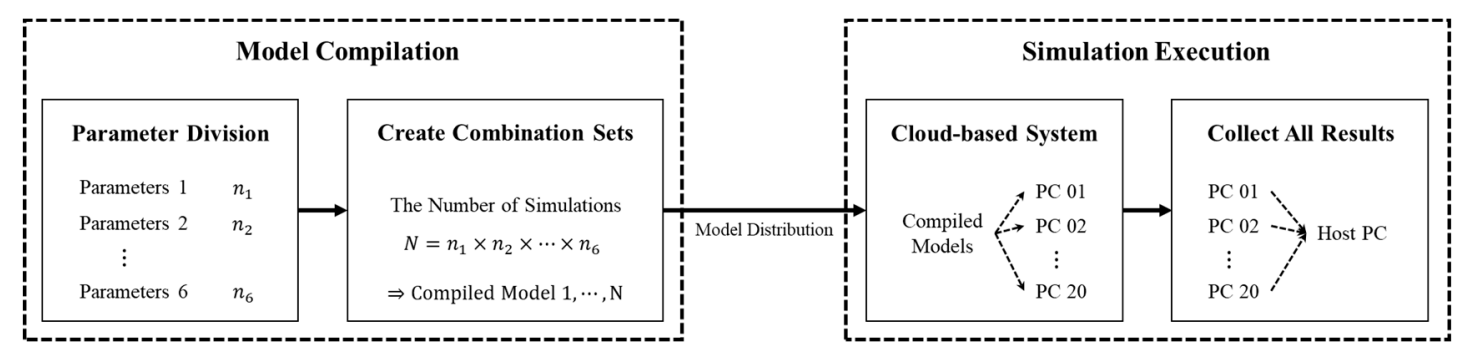

Figure 9. Large-scale simulation under the cloud-based system.

In this study, six parameters are selected to be optimized as shown in Table 2, and about six to 20 candidates within the upper and lower boundaries are used according to the selected parameters, resulting in over a million runs to investigate all combinations of the parameters. Further, the total number of simulations is multiplied by the number of the cycles, causing the complexity of the optimization to increase exponentially. Therefore, distributed computing is necessary to obtain the fuel consumption values from all combinations. By using the model compilation with Matlab rsim target, the computation time for each simulation was reduced to $3 \mathrm{~s}$. Thus, LSS for over about a million iterations was completed in about $10 \mathrm{~h}$. All simulation results obtained from LSS are shown in Figure 10, in which each grey point indicates the final fuel consumption value with respect to the final SOC from a single simulation. Based on the results, a blue frontier line can be obtained by connecting the points of the lowest fuel consumption for each final SOC. According to Equations (10) and (11), the optimal solution of the control problem, represented by a blue dot, is obtained on the frontier line when the final SOC is the same as the initial SOC, which is $60 \%$ in the problem. LSS, however, does not always guarantee satisfaction of the constraint, despite the increasing number of combinations. Therefore, the SOC tolerance is set based on two decimal places and the lowest point within the designated SOC range is the best point, which is expressed as shown in Equation (12).

$$
\min m_{\text {fuel }}\left(t_{f}\right), \quad 59.995 \leq S O C_{\text {final }}<60.005 .
$$




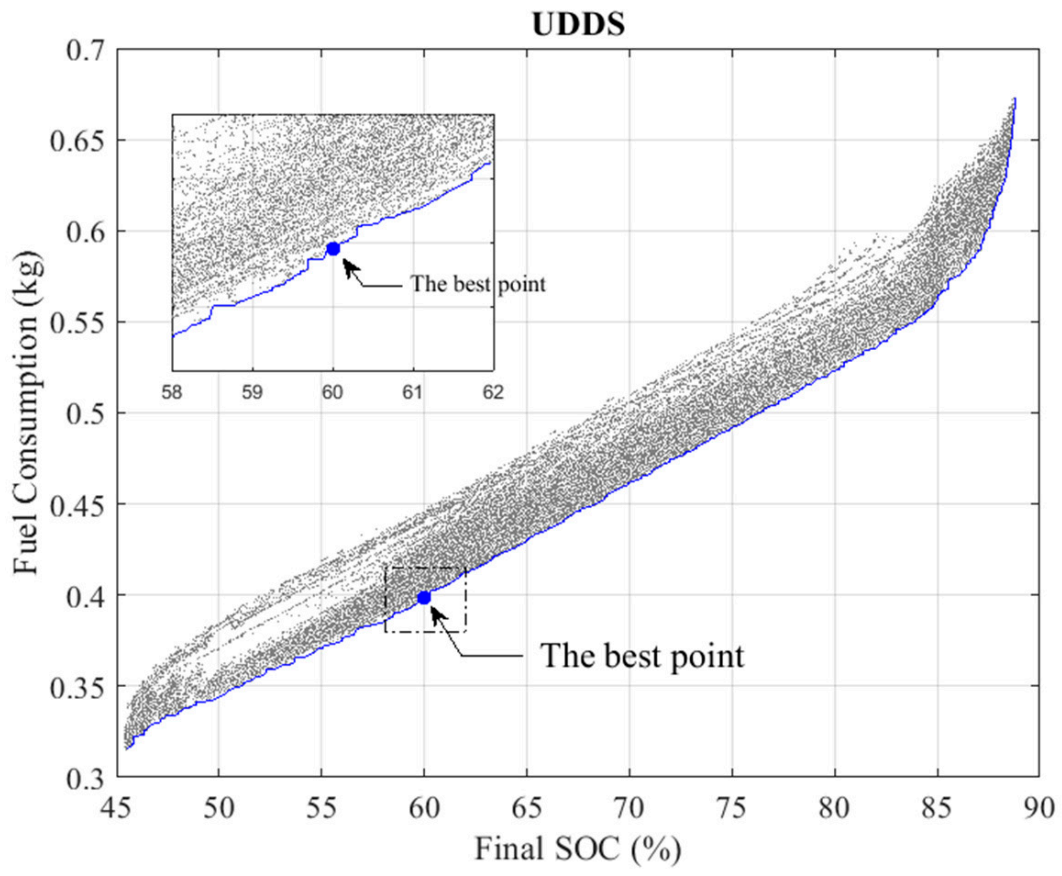

Figure 10. All results of the rule-based control through the large-scale simulation (UDDS cycle).

The LSS method introduced in this study is useful because it not only provides near absolute solutions, but also other analyses can be made possible from the simulation results. For instance, the results in Figure 10 show the impact of the electrical energy use on the fuel consumption; in addition, it is possible to analyze the impact of the control parameters on the fuel consumption based on the results obtained from LSS.

\subsection{Pattern Search (PS)}

The PS is a numerical optimization method that directly searches for the best parameter set by minimizing an objective function such that given constraints are satisfied. In each step, a process called polling is used to find the best points out of available points in a pre-defined mesh consisting of a pattern vector. The procedure continues to the next iteration when either the best points are found, or all cases are computed. The mesh size, $s$, is a scalar value and is expanded or contracted depending on whether the polling succeeded in the previous iteration. In particular, the PS method offered by Matlab uses the Augmented Lagrangian Pattern Search (ALPS) algorithm to solve nonlinear constraint as shown in Equation (16) [32]. The flow chart for the PS algorithm in Figure 11 shows how Equations (13)-(16) are solved using polling.

$$
\begin{gathered}
\min _{x} f(x)=\min _{x} m_{f c}\left(t_{f}\right), \\
c(x)=S O C_{\text {final }}(x)-60 \geq 0,
\end{gathered}
$$

lower bounds $\leq x \leq$ upper bounds,

$$
l(\boldsymbol{x}, \boldsymbol{\lambda})=f(\boldsymbol{x})-\sum_{i=1}^{m} \lambda_{i} c(\boldsymbol{x}) .
$$




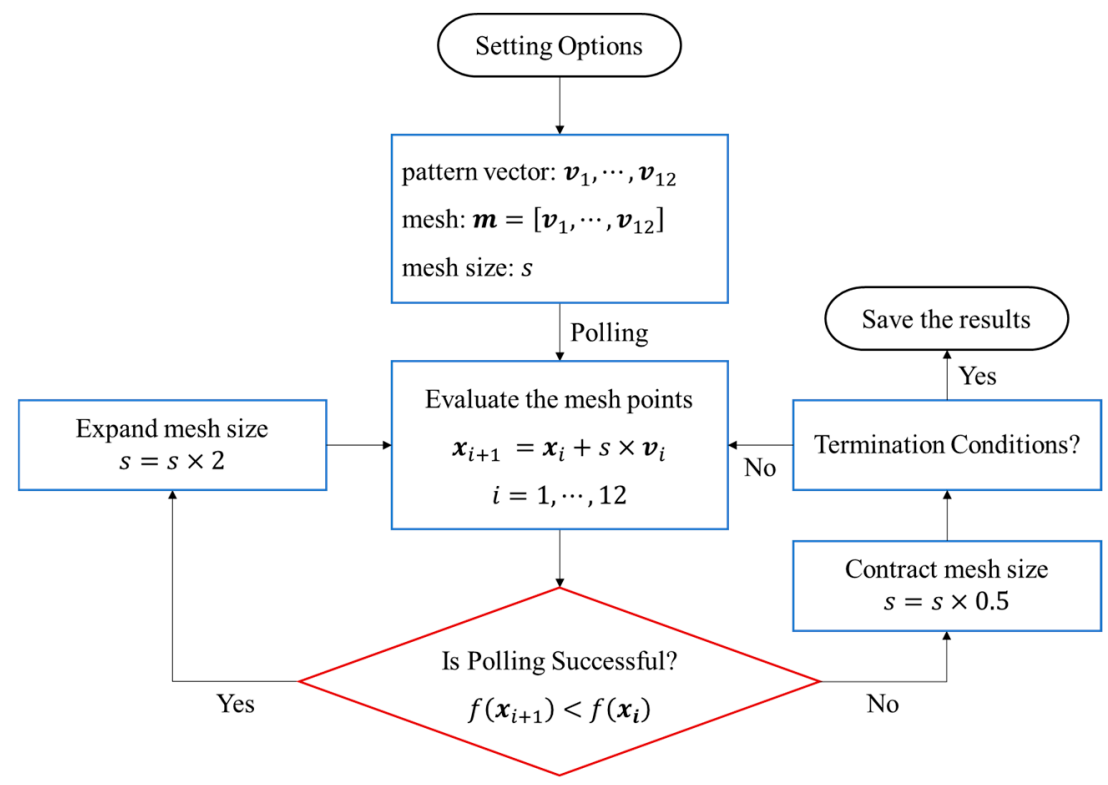

Figure 11. Flow chart for the pattern search algorithm.

The algorithm, however, works slightly differently depending on the initial conditions, because the process may produce solutions that are only locally optimal. However, Matlab provides an optimization toolbox to investigate a wide range of parameter sets, so as to decrease the chances of finding an only locally optimal solution instead of taking more time to find the optimal parameters. The number of the pattern vector $v$ is two times greater than that of the control variables. The total number of simulations run in PS was about 4500, as shown in Figure 12, which was much smaller than the simulations run in LSS, even though it takes into account that PS has a higher computation time per simulation than LSS. Based on the pattern search algorithm, optimal results were obtained as shown in Figure 12. In the pattern search process shown, several points do not follow the overall converging tendency, but the results eventually converge to an optimal value.

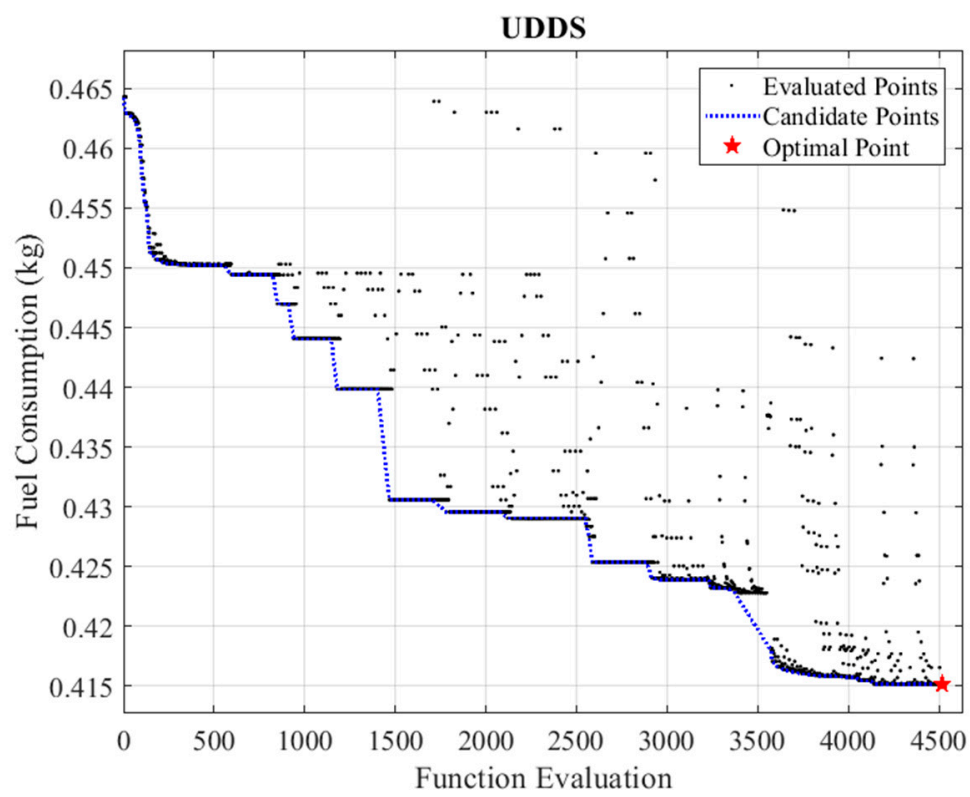

Figure 12. Pattern search optimization process. 
The advantage of the pattern search is that it is possible to obtain optimal control parameters within a reasonable calculation time. The solution, however, does not provide additional information to understand the control problem. Therefore, comparing the performances of the two different processes, LSS and PS, could provide hints to other engineers that would aid them in selecting an appropriate approach for developing a rule-based controller.

\subsection{Pontryagin's Minimum Principle}

A PMP-based control has been considered as an optimal solution to the HEV control problem. The control concept utilizes optimal control maps that minimize a Hamiltonian, which can be interpreted as an equivalent fuel consumption [20,21]. The optimal maps such as engine on/off map, operating mode map, engine torque map, and gear shifting map are obtained by minimizing the Hamiltonian according to the optimal costate, where the costate has the physical meaning of the equivalent factor between gas fuel consumption and electrical energy consumption. The sum of the two consumptions is defined as the Hamiltonian, which can be expressed as follows:

$$
\min H=\dot{m}_{f c}\left(P_{b a t}, t\right)+\lambda \cdot \operatorname{SOC}\left(\mathrm{SOC}, P_{b a t}\right) .
$$

The absolute value of $\lambda$ represents the relative price of the electrical energy to the fuel energy. Thus, the usage pattern of the electrical energy depends on $\lambda$. The main problem in the PMP-based control is to find out an appropriate $\lambda$ to ensure that the final SOC is the same as the initial SOC $[20,21]$. However, multiple SOC trajectories generated by using different $\lambda$, as shown in Figure 13a, are used in this study because they are the best fuel consumption values for the final achieved SOC. Therefore, they can be reference fuel consumptions. The final fuel consumption for each trajectory is plotted with respect to the final SOC, and the best fuel consumption line is obtained as shown in Figure 13b.

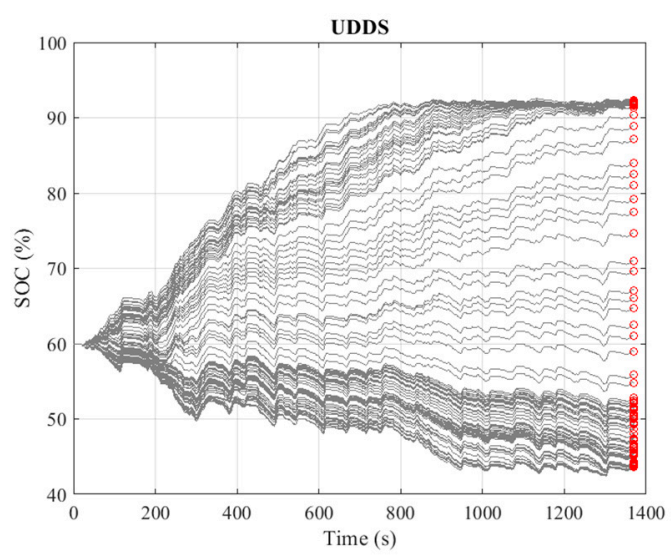

(a)

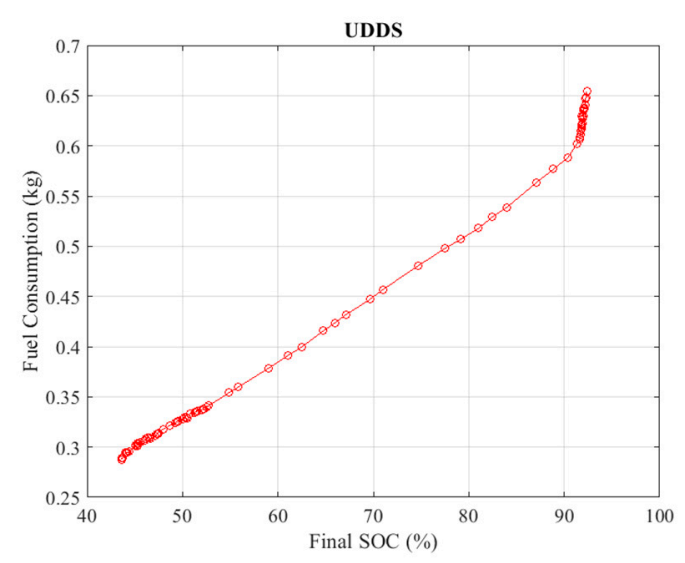

(b)

Figure 13. (a) SOC trajectories according to the range of the costates (UDDS cycle); (b) minimum fuel consumption line against SOC obtained from the Pontryagin's minimum principle (PMP) (UDDS cycle). The fuel consumption highly increases if the SOC is over $90 \%$ because the vehicle cannot recuperate the braking energy.

As has been stated, every single SOC trajectory in Figure 13a is the optimal trajectory for each final SOC. Therefore, the line obtained in Figure $13 \mathrm{~b}$ can be considered the minimum fuel consumption line and be used to evaluate the performance of the rule-based control. The advantage of obtaining the line is that it is possible to evaluate another controller's performance by investing the margin to the reference line even if its final SOC is not the same as the initial SOC. 


\section{Comparative Results}

In order to see the performance of the proposed rule-based control and the two parametric optimization processes, the fuel consumption values obtained from LSS and PS are shown in Figure 14 In the figure, the final fuel consumption value obtained by PS is added, where the results from LSS in Figure 10 and the results from the PMP in Figure 13b are copied to the figure.

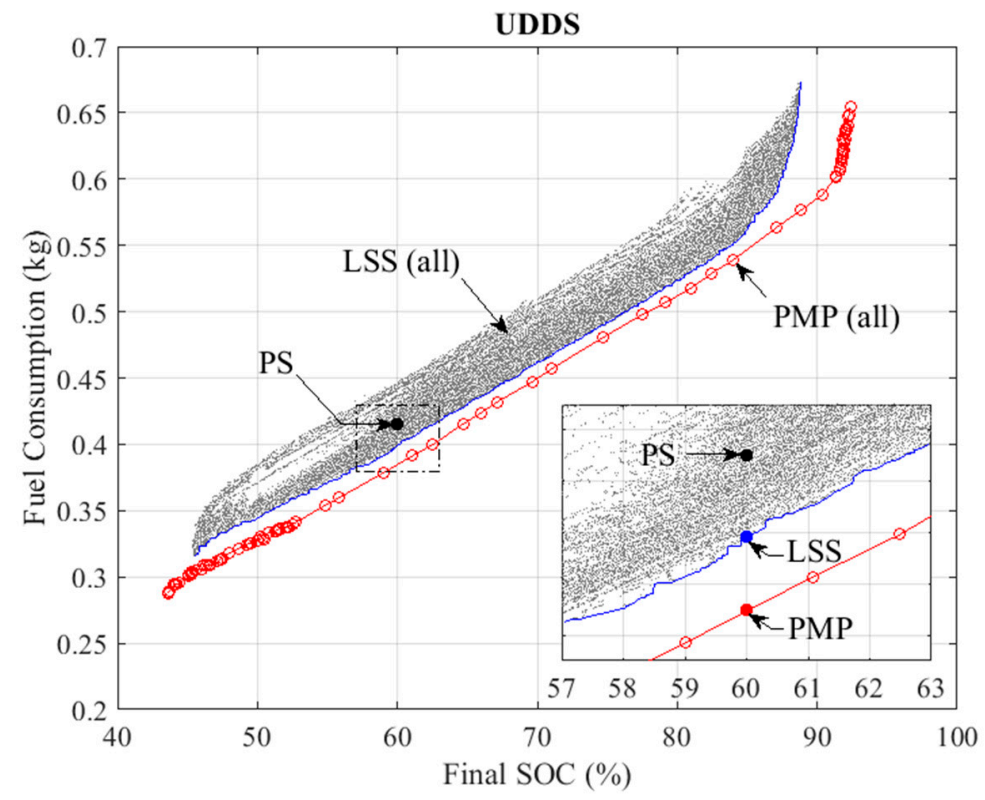

Figure 14. Fuel consumption results obtained from the large-scale simulation (LSS), the pattern search (PS), and the PMP (UDDS cycle).

Based on the results, it is possible to understand the performance limitation of the rule-based control. A rule-based control is very robust, but it is not possible to design the controller to always produce the best operating behaviors. Although the best control parameters are selected, the rule-based control cannot outperform the PMP-based control, which is quite natural, but the results in Figure 14 shows how close the rule-based control can be to the optimal results. Further, the results also show that the performance can be different if a different optimization process is used to find the control parameters. In the results, the control parameters obtained by PS consumes additional fuel by $4 \%$ in UDDS, as compared to the control parameters obtained by LSS (see Table 3). In addition, the performances of the control parameters according to different optimization processes are compared in UDDS, and the comparative study is conducted for other representative cycles. The fuel consumption obtained when the final SOC is the same as the initial SOC, or $60 \%$, is used to compare the performances of the controls, as shown in Figure 14, and the results are summarized in Table 3. Equation (18) is used to analyze the results and to find out the potential improvement degree of the rule-based control. The potential improvement degree represents the possibility to achieve an improved performance in the case of modifying the rule-based controller.

$$
\text { Potential Improvement Degree }(\%)=\frac{m_{f c}^{L S S, P S}\left(t_{f}\right)-m_{f c}^{P M P}\left(t_{f}\right)}{m_{f c}^{P M P}\left(t_{f}\right)} \times 100 .
$$


Table 3. Fuel consumption results according to different methods for parametric optimization.

\begin{tabular}{cccc}
\hline Driving Cycle & PMP (Reference) & LSS & PS \\
\hline HWFET & $0.542 \mathrm{~kg}$ & $0.543 \mathrm{~kg}(+0.18 \%)$ & $0.551 \mathrm{~kg}(+1.66 \%)$ \\
SC03 & $0.194 \mathrm{~kg}$ & $0.197 \mathrm{~kg}(+1.55 \%)$ & $0.201 \mathrm{~kg}(+3.61 \%)$ \\
UDDS & $0.385 \mathrm{~kg}$ & $0.399 \mathrm{~kg}(+3.64 \%)$ & $0.415 \mathrm{~kg}(+7.79 \%)$ \\
US06 & $0.599 \mathrm{~kg}$ & $0.600 \mathrm{~kg}(+0.17 \%)$ & $0.612 \mathrm{~kg}(+2.17 \%)$ \\
WLTC & $0.827 \mathrm{~kg}$ & $0.849 \mathrm{~kg}(+2.66 \%)$ & $0.862 \mathrm{~kg}(+4.23 \%)$ \\
Average Difference & - & $+1.63 \%$ & $+3.89 \%$ \\
\hline
\end{tabular}

The results in Figure 15 show that the rule-based controls with optimized parameters have a quite good performance, close to that of the PMP-based control. The average performance differences for LSS and PS are $1.63 \%$ and 3.89\%, respectively, and LSS outperforms PS for all cycles in Table 3. Figure 16 shows both the maximum performance and the potential improvement of the rule-based controller for all driving cycles. Setting the initial or the starting points for PS is important because the final results may be significantly affected by the initial points in nonlinear problems, which may produce local optimal solutions. Thus, the results obtained by PS have lower performances than the results obtained by LSS, even though we tried to avoid finding locally optimal results. The rule-based control, whatever the method used for the parametric optimization, showed deficient performance especially in UDDS and WLTC, compared to other driving cycles, which implies that the rule-based control has limitations for maximizing fuel efficiency when the vehicle engages in urban driving cycles where accelerating events occur frequently. The results obtained in this study can provide good references to select an appropriate control organization and a process to find optimal control parameters in that the results show the differences of the performances among the control processes. However, additional studies are necessary to develop a realistic controller using the rule-based control concept because the optimal control parameters can be very different in a specific driving condition. Therefore, extensive studies about the impact of the driving conditions on the control parameters should follow this study, and we are working on a sensitivity analysis of the control parameters based on a large number of simulation results obtained by LSS.

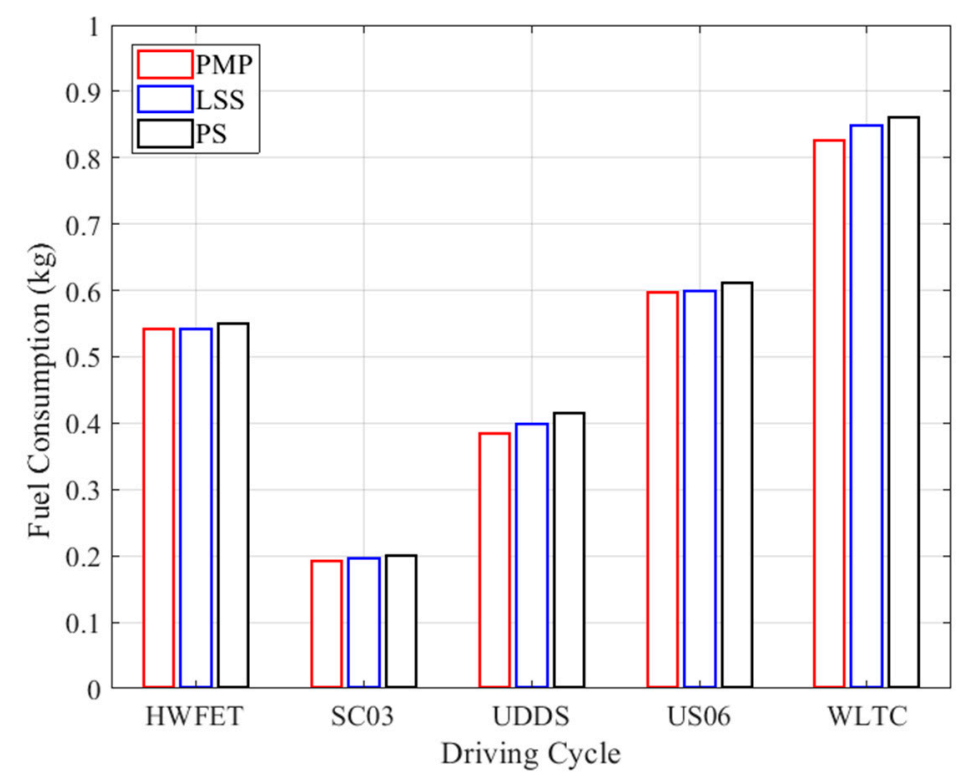

Figure 15. Performance comparison based on PMP results for five driving cycles. 


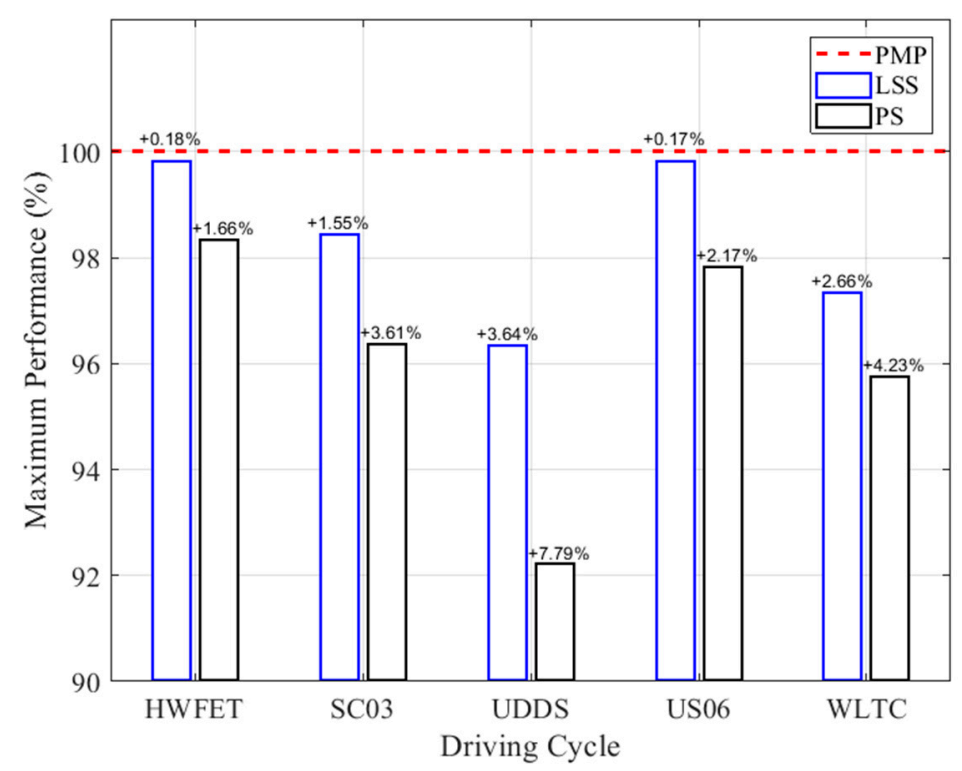

Figure 16. Maximum performance and potential improvement degree of the rule-based control for five driving cycles.

\section{Conclusions}

HEV controllers based on optimal control theories like DP and PMP produce optimal fuel efficiencies but have unsolved technical matters; thus, rule-based controls have been used in most HEVs in the real-world vehicle market. One main problem with the PMP-based control is that it guarantees optimality only when future information is available. Thus, although the PMP-based control provides outstanding performances in fuel efficiency, it is not likely to supplant the rule-based control method. In this study, a control organization using control parameters was proposed for a rule-based concept. Two methods, large-scale simulation (LSS) and pattern search (PS), were applied to find the optimal parameters that maximize fuel efficiency. LSS exhaustively examines a large number of combinations for the control parameters, whereas PS directly searches the best parameters based on an optimization process. Therefore, LSS produces a better control parameter set than PS, but PS saves the computational time to find the parameter set. This study provides insight into three things that could be very useful as a general reference in designing rule-based controls. First, a control organization of the rule-based concept for engine on/off and power distribution is provided. Second, key control parameters that significantly affect the control aspects are defined, and two processes to optimize the parameters are proposed. Third, the performance of the rule-based control is evaluated by comparing its results with the optimal results obtained by the PMP. Based on the comparative results, the rule-based control with optimized parameters can achieve a feasible performance close to that of the PMP-based control, which demands additional fuel consumptions by $1.63 \%$ in LSS and $3.89 \%$ in PS. While it is still considered that designing supervisory controllers based on heuristic rules with optimized parameters is a feasible approach for real-world HEVs, this study provides the marginal boundary of the performance of the rule-based control and the impact of the optimization process.

Author Contributions: Conceptualization, H.J. and N.K.; Project administration, N.K.; Software, H.J. and K.L.; Visualization, H.J.; Writing—original draft, H.J.; Writing—review and editing, N.K.

Funding: This work was supported by the Korea Institute of Energy Technology Evaluation and Planning (KETEP) and the Ministry of Trade, Industry and Energy (MOTIE) of the Republic of Korea (No. 20172010104970). This work was also supported by the Technology Innovation Program (20002762, Development of RDE DB and Application Source Technology for Improvement of Real Road $\mathrm{CO}_{2}$ and Particulate Matter) funded by the Ministry of Trade, Industry and Energy (MOTIE, Korea).

Conflicts of Interest: The authors declare no conflict of interest. 


\section{References}

1. Capellán-Pérez, I.; Mediavilla, M.; de Castro, C.; Carpintero, Ó.; Miguel, L.J. Fossil fuel depletion and socio-economic scenarios: An integrated approach. Energy 2014, 77, 641-666. [CrossRef]

2. Jackson, R.; Le Quéré, C.; Andrew, R.; Canadell, J.; Peters, G.; Roy, J.; Wu, L. Warning signs for stabilizing global $\mathrm{CO}_{2}$ emissions. Environ. Res. Lett. 2017, 12, 110202. [CrossRef]

3. Abrell, J. Regulating $\mathrm{CO}_{2}$ emissions of transportation in Europe: A CGE-analysis using market-based instruments. Transp. Res. D Transp. Environ. 2010, 15, 235-239. [CrossRef]

4. Nejat, P.; Jomehzadeh, F.; Taheri, M.M.; Gohari, M.; Majid, M.Z.A. A global review of energy consumption, $\mathrm{CO}_{2}$ emissions and policy in the residential sector (with an overview of the top ten $\mathrm{CO}_{2}$ emitting countries). Renew. Sustain. Energy Rev. 2015, 43, 843-862. [CrossRef]

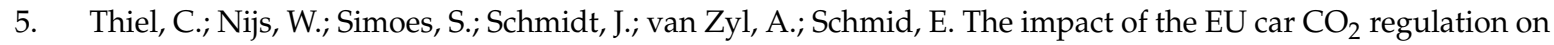
the energy system and the role of electro-mobility to achieve transport decarbonisation. Energy Policy 2016, 96, 153-166. [CrossRef]

6. Bayindir, K.Ç.; Gözüküçük, M.A.; Teke, A. A comprehensive overview of hybrid electric vehicle: Powertrain configurations, powertrain control techniques and electronic control units. Energy Convers. Manag. 2011, 52, 1305-1313. [CrossRef]

7. Kim, N.; Kwon, J.; Rousseau, A. Comparison of powertrain configuration options for plug-in HEVs from a fuel economy perspective. SAE Tech. Pap. 2012.

8. Li, C.-T.; Zhang, X.; Peng, H. Design of power-split hybrid vehicles with a single planetary gear. In Proceedings of the ASME 2012 5th Annual Dynamic Systems and Control Conference Joint with the JSME 2012 11th Motion and Vibration Conference, Fort Lauderdale, FL, USA, 17-19 October 2012; pp. 857-865.

9. Staunton, R.H.; Ayers, C.W.; Marlino, L.; Chiasson, J.; Burress, B. Evaluation of 2004 Toyota Prius Hybrid Electric Drive System; Oak Ridge National Lab: Oak Ridge, TN, USA, 2006.

10. Liu, J.; Peng, H.; Filipi, Z. Modeling and analysis of the Toyota hybrid system. In Proceedings of the 2015 IEEE/ASME Interntaional Conference on Advanced Intelligent Mechatronics, Montery, CA, USA, 24-28 July 2015; pp. 134-139.

11. Rousseau, A.; Sharer, P.; Pasquier, M. Validation process of a HEV system analysis model: PSAT. SAE Tech. Pap. 2001.

12. Fulton, L. Ownership cost comparison of battery electric and non-plugin hybrid vehicles: A consumer perspective. Appl. Sci. 2018, 8, 1487.

13. Baumann, B.M.; Washington, G.; Glenn, B.C.; Rizzoni, G. Mechatronic design and control of hybrid electric vehicles. IEEE ASME Trans. Mechatron. 2000, 5, 58-72. [CrossRef]

14. Barsali, S.; Miulli, C.; Possenti, A. A control strategy to minimize fuel consumption of series hybrid electric vehicles. IEEE Trans. Energy Convers. 2004, 19, 187-195. [CrossRef]

15. Paganelli, G.; Ercole, G.; Brahma, A.; Guezennec, Y.; Rizzoni, G. General supervisory control policy for the energy optimization of charge-sustaining hybrid electric vehicles. JSAE Rev. 2001, 22, 511-518. [CrossRef]

16. Musardo, C.; Rizzoni, G.; Guezennec, Y.; Staccia, B. A-ECMS: An adaptive algorithm for hybrid electric vehicle energy management. Eur. J. Control 2005, 11, 509-524. [CrossRef]

17. Onori, S.; Serrao, L. On adaptive-ECMS strategies for hybrid electric vehicles. In Proceedings of the International Scientific Conference on Hybrid and Electric Vehicles, Malmaison, France, 6-7 December 2011.

18. Lin, C.-C.; Peng, H.; Grizzle, J. A stochastic control strategy for hybrid electric vehicles. In Proceedings of the 2004 American Control Conference, Boston, MA, USA, 30 June-2 July 2004; pp. 4710-4715.

19. Moura, S.J.; Fathy, H.K.; Callaway, D.S.; Stein, J.L. A stochastic optimal control approach for power management in plug-in hybrid electric vehicles. IEEE Trans. Control Syst. Technol. 2011, 19, 545-555. [CrossRef]

20. Kim, N.; Cha, S.; Peng, H. Optimal control of hybrid electric vehicles based on Pontryagin's minimum principle. IEEE Trans. Control Syst. Technol. 2011, 19, 1279-1287.

21. Kim, N.; Lee, D.; Zheng, C.; Shin, C.; Seo, H.; Cha, S. Realization of pmp-based control for hybrid electric vehicles in a backward-looking simulation. Int. J. Automot. Technol. 2014, 15, 625-635. [CrossRef]

22. Yuan, Z.; Teng, L.; Fengchun, S.; Peng, H. Comparative study of dynamic programming and Pontryagin's minimum principle on energy management for a parallel hybrid electric vehicle. Energies 2013, 6, 2305-2318. [CrossRef] 
23. Thomas, J. Drive cycle powertrain efficiencies and trends derived from EPA vehicle dynamometer results. SAE Int. J. Passeng. Cars Mech. Syst. 2014, 7, 1374-1384. [CrossRef]

24. Vijayagopal, R.; Michaels, L.; Rousseau, A.P.; Halbach, S.; Shidore, N. Automated model based design process to evaluate advanced component technologies. SAE Tech. Pap. 2010.

25. EPA (U.S. Environmental Protection Agency). Model Year 2017 Fuel Economy Guide; EPA: Washington, DC, USA, 2017.

26. Ma, C.; Ji, J.; Choi, W.; Kim, H. A study on control algorithm and energy management strategy for GM-volt plug-in HEV. In Proceedings of the KSAE 2011 Annual Conference and Exhibition, Daejeon, Korea, 23-26 November 2011; pp. 2755-2761.

27. Cheng, Y.-H.; Lai, C.-M. Control strategy optimization for parallel hybrid electric vehicles using a memetic algorithm. Energies 2017, 10, 305. [CrossRef]

28. Lei, Z.; Cheng, D.; Liu, Y.; Qin, D.; Zhang, Y.; Xie, Q. A dynamic control strategy for hybrid electric vehicles based on parameter optimization for multiple driving cycles and driving pattern recognition. Energies 2017, 10, 54. [CrossRef]

29. Hussein, M.M.; Mahmoud, K.; Abdel-Nasser, M. Optimal voltage control considering PV-inverter and OLTC using grey wolf optimizer. In Proceedings of the 2018 International Conference on Innovative Trends in Computer Engineering (ITCE), Aswan, Egypt, 19-21 Feburary 2018; pp. 473-477.

30. Zhang, Y.; Sun, F.; He, H. Control strategy optimization for hybrid electric vehicle based on DIRECT algorithm. In Proceedings of the 2008 IEEE Vehicle Power and Propulsion Conference, Harbin, China, 3-5 September 2008.

31. Deng, T.; Lin, C.; Luo, J.; Chen, B. NSGA-II multi-objectives optimization algorithm for energy management control of hybrid electric vehicle. Proc. Inst. Mech. Eng. Part D J. Automob. Eng. 2019, 233, 1023-1034. [CrossRef]

32. Conn, A.; Gould, N.; Toint, P. A globally convergent Lagrangian barrier algorithm for optimization with general inequality constraints and simple bounds. Math. Comput. Am. Math. Soc. 1997, 66, 261-288. [CrossRef]

33. Park, J. Development of engine clutch control for parallel hybrid vehicles. In Proceedings of the 2013 World Electric Vehicle Symposium and Exhibition (EVS27), Barcelona, Spain, 17-20 November 2013; pp. 1-5.

34. Mansour, C.; Clodic, D. Dynamic modeling of the electro-mechanical configuration of the Toyota Hybrid System series/parallel power train. Int. J. Automot. Technol. 2012, 13, 143. [CrossRef]

35. Gupta, A.; Ramanarayanan, C. Analysis of circulating power within hybrid electric vehicle transmissions. Mech. Mach. Theory 2013, 64, 131-143. [CrossRef]

36. Petric, J. A power-split hybrid hydraulic vehicle transmission modeling and comparative analysis. SAE Tech. Pap. 2010.

37. Kim, N.; Rousseau, A.; Rask, E. Vehicle-level control analysis of 2010 Toyota Prius based on test data. Proc. Inst. Mech. Eng. Part. D 2012, 226, 1483-1494. [CrossRef]

38. Du, J.; Yang, F.; Cai, Y.; Du, L.; Ouyang, M. Testing and analysis of the control strategy of Honda Accord plug-in HEV. IFAC Pap. 2016, 49, 153-159. [CrossRef]

(C) 2019 by the authors. Licensee MDPI, Basel, Switzerland. This article is an open access article distributed under the terms and conditions of the Creative Commons Attribution (CC BY) license (http://creativecommons.org/licenses/by/4.0/). 